\title{
EM BUSCA DA ÉTICA
}

\section{In pursuit of ethics}

\author{
Lawrence Buell* \\ Tradução: André L. M. L. de Scoville
}

Mesmo sem tornar-se - ao menos até o momento - um conceito paradigmático como foi a textualidade na década de 1970 e o historicismo na década de 1980, a Ética ganhou nova e ampla repercussão dentro dos estudos literários nos últimos anos. ${ }^{1}$

Como acontece com qualquer forte tendência que surge, particularmente quando o termo central de referência já faz parte do uso corrente, o desafio de definir o que efetivamente é Ética intensifica-se na mesma proporção do número de segmentos que se propõem a fazê-lo. 0 caráter abrangente descrito na "chamada de trabalhos" para esta edição especial de Publications of the Modern Language Association of America (PMLA), parcialmente reproduzida abaixo, confirma a evidente heterogeneidade:

A ética da leitura, escrita, crítica, interpretação, teoria e ensino. As dimensóes éticas de linhas críticas e teóricas particulares [...]. A ética dos discursos, gêneros e instituições culturais [...]. A pertinência para os estudos literários dos [...] modelos provenientes da filosofia moral e política. [...] A retórica da literatura ética. [...] As ramificações éticas de aspectos da cultura profissional [...].

Lawrence Buell, Ph.D. pela Universidade de Cornell, é professor de literatura americana na Universidade de Harvard, onde já exerceu a chefia do departamento de língua e literatura americana e inglesa. Seu livro Emerson, publicado em 2003, ganhou o prêmio Warren-Brooks de crítica literária. Dentre suas áreas de estudo, destaca-se a Ecocrítica ou Crítica Ambiental (Environmental Criticism). Em busca da ética (In pursuit of ethics) é o texto de introdução do número temático sobre ética e estudos literários da revista Publications of the Modern Language Association of America (PMLA), v. 114, n. 1, jan. 1999. André Scoville é doutorando em Letras pela Universidade Federal do Paraná.

1 Entre os autores e livros de teoria e crítica literária que se dedicam integralmente ou principalmente à ética, a partir de 1987, temos: Miller (Ethics e Versions), Booth (Company), Nussbaum (Love's Knowledge e Poetic Justice), Siebers, Harpham (Getting), Parker, Norris, Newton (Narrative Ethics) e Eaglestone. Também notável é o crescimento recente do número de livros que, mesmo sem tratarem primordialmente da questão ética, incluem a palavra "ética" no título ou subtítulo (por exemplo: Phelan; Chow). 
Os quarenta e seis trabalhos que foram apresentados também demonstram, como se alguma outra prova ainda fosse necessária, que não existe um "movimento ético" uniforme, tampouco um sólido consenso entre os membros do Modern Language Association of America (MLA) no que diz respeito a enfatizar-se algum tipo específico de estudo ético. Esse discurso multifacetado entrelaça-se com muitas linhas genealógicas, e sobre seis das quais eu passo a comentar brevemente antes de focalizar alguns pontos de vista específicos do conjunto de estudos formado até aqui, entre eles, os cinco minuciosos e incisivos ensaios que o Conselho Editorial selecionou para esta publicação."

A primeira e mais duradoura dessas linhas genealógicas é herança das tradições críticas que enfatizavam as temáticas morais e os compromissos com valores subjacentes dos textos literários e seus respectivos autores. A abordagem de David Parker (1994, p. 77-78, 120-122, 152) para a ficção, por exemplo, parece, até certo ponto, a atualização sutil e relativizada de uma concepção arnoldiana-leavisiana de literatura como uma reflexão ética. Uma tradição semianáloga nos estudos literários dos Estados Unidos tem sido a história intelectual do pensamento moral desde o puritanismo ao transcendentalismo, ao pragmatismo; um legado recentemente "multiculturalizado" - como os pensadores afroamericanos têm se posicionado a respeito - que começou com W. E. B. Du Bois (WEST, p. 138150; PATTERSON, p. 159-197), ex-aluno de William James. Essa tendência está representada nesta edição da PMLA pela análise de James M. Albrecht sobre o modo como Ralph Waldo Emerson interessava a Ralph Waldo Ellison. Em termos de difusão, a maior influência sobre os estudos literários tradicionais tem sido a teoria e crítica ética que focaliza a retórica do gênero, tal como a obra de Wayne Booth, que, ao longo de várias décadas, tratou a retórica narrativa como uma moral imagination e que continua sendo uma referência para os estudos mais recentes (por exemplo, Phelan, Newton e Yúdice - para citar autores cujas reações vão da simpatia à crítica contundente).

** NT: Os trabalhos publicados nesta edição de PMLA foram: Innovation, Literature, Ethics: Relating to the Other ("Inovação, Literatura, Ética: A Relação com o 'Outro'”) por Derek Attridge; Aesthetics and Ethics in Gadamer, Levinas, and Romanticism: Problems of Phronesis and Techne ("Estética e Ética em Gadamer, Levinas e o Romantismo: Problemas de Phronesis e Techne") por David P. Haney; Saying Yes and Saying No: Individualist Ethics in Ellison, Burke, and Emerson ("Dizer Sim e Dizer Não: A Ética Individualista em Ellison, Burke e Emerson") por James M. Albrecht; Ethical Value and Negative Aesthetics: Reconsidering the Baudrillard-Ballard Connection ("O Valor Ético e Estética Negativa: Reavaliando a Conexão Baudrillard-Ballard") por Bradley Butterfield; e Testimony, Ethics, and the Aesthetic in Diamela Eltit (“Testemunho, Ética e Estética em Diamela Eltit”) por Mary Beth Tierney-Tello. 
Relacionada com essa linha, pode-se apontar uma segunda perspectiva que é o olhar recíproco que alguns filósofos (particularmente Martha Nussbaum e Richard Rorty) dirigem à literatura. Podem ser mencionados: o argumento de Nussbaum (1990, p. 125-219) de que as reflexões morais ricamente contextualizadas dos romances de Henry James propiciam um complemento necessário para o estudo da filosofia moral (uma abordagem que, aliás, ela já empregara com outros autores e em Poetic justice); a caracterização, elaborada por Rorty, da filosofia como um "tipo de literatura" (1982, p. 90-109), o que consistiria numa alternativa para o que ele acredita ser o beco sem saída da epistemologia; e ainda (mais recente e pertinentemente) a abordagem de Rorty de (algumas) obras literárias como corporificações modelares de valores sociais (1989, p. 141188). Esses estudos, no entanto, interessaram aos teóricos no campo da literatura menos por causa de alguma originalidade radical do método do que pelo fato de haverem cooperado para o ressurgimento da abordagem orientada para os valores morais e sociais dentro dos estudos literários.

Mais importantes para a definição do formato das "agendas específicas" dos estudos literários foram dois outros processos, os quais dizem respeito às reações decorrentes das transformações do modo de pensar de/a respeito de duas figuras de grande impacto sobre a teoria literária do pós-estruturalismo dos anos 1970 e 1980: Jacques Derrida e Michel Foucault.

A reavaliação da ética do desconstrutivismo é o mais dramático desses processos, uma vez que está relacionada com a "queda" do seu proeminente representante americano, Paul de Man, como consequência da publicação póstuma de artigos escritos durante a II Grande Guerra, que demonstravam seu colaboracionismo com o nazismo. Em um ensaio cuja circunstância de produção é ela própria uma referência para a recente "voga ética", ${ }^{2}$ Geoffrey Harphan, com certa ironia, comenta este "acontecimento" que "em, ou por volta de, $1^{\circ}$ de dezembro de 1987 , mudou a natureza da teoria literária" (1995, p. 389). De fato, Wartime journalism de De Man desencadeou uma série de controvérsias dentro e fora da academia sobre o caráter evasivo ou a possível iniquidade moral do desconstrutivismo. Este fato intensificou a crítica que acusava de ser eticamente míope o postulado de Derrida que apregoava o estudo de "nada fora do texto" (textualidade) e, muito provavelmente, tem alguma relação com o aumento do engajamento social, político e ético de Derrida nos últimos anos. Todavia o desconstrutivismo (e o pós-estruturalismo, de modo mais amplo) já havia revelado uma perspectiva ética distinta - mesmo não sendo assim denominada e mesmo com o propósito de negar - principalmente ao "compelir-nos a refletir sobre os custos do absolutismo moral, sobre a

${ }^{2}$ A edição original (1990) do Critical Terms for Literary Study, de Lentricchia e McLaughlin, não possuía o verbete "ética"; o ensaio de Harpham foi incluído na segunda edição (1995). 
violência latente na tentativa de construir modos de vida eticamente completos e acabados" (JAY, 1993, p. 46-47). Duas correntes éticas preexistentes dentro do movimento desconstrutivista, as quais ganharam força no fim dos anos 1980, foram: a defesa da "rigorosa inconfiabilidade" na ideia de a "leitura crítica" em si poder ser vista como uma ética (JOHNSON, 1987, p. 17-24; MILLER, 1987); e, especialmente, o diálogo, ao longo de várias décadas, entre Derrida e Emmanuel Levinas. Este diálogo culminou, após a morte de Levinas, na afirmação de Derrida de que "o pensamento de Levinas nos despertou" para uma concepção de "uma responsabilidade 'ilimitada' que ultrapassa e precede minha liberdade" (DERRIDA, 1996, p. 3), isto depois de Levinas - entre Totality and infinity (1961) e Otherwise than being (1974) haver desenvolvido seu argumento de uma "ética como sendo uma primeira filosofia" (a prioridade da obrigação ética para com o outro na ontologia, no próprio ser) em resposta à crítica de Derrida em "Violence and Metaphysics" a respeito de Totality and infinity. Se Levinas tornou-se o teórico mais importante para o grupo pós-pós-estruturalista de estudos éticoliterários na virada do século, e existem muitas evidências disso (CRITCHLEY; NEALON; NEWTON, 1995; EAGLESTONE; assim como os ensaios de Derek ATTRIDGE e David P. HANEY), uma boa parte do crédito deve-se a Derrida por ter chamado a atenção da academia para o trabalho de Levinas.

Da mesma forma que a mudança dentro do desconstrutivismo, motivada por qualquer combinação de pressões internas e externas, conferiu nova proeminência à reflexão sobre responsabilidade ética pelo outro, a crescente atenção recentemente dada ao "sujeito" (subjectness) e à "agência" (agency) foi incorporada no redirecionamento de ênfase das últimas obras de Michel Foucault. Em History of sexuality, Foucault mudou seu enfoque sobre a problemática do "poder-saber" e sobre a construção dos indivíduos sociais pelas macroinstituições discursivas para o "cuidar de si" como um projeto ético, uma mudança acelerada pela percepção de que, no que concerne aos homens privilegiados da antiguidade grega e romana, "a reflexão sobre o comportamento sexual como um campo moral não constituiu entre eles um meio de internalizar, justificar ou formalizar as interdições gerais impostas a todos", mas uma "estética da existência" (1985, p. 252-253)"*, ou, de fato, uma "ética do prazer" (1986, p. 239). ${ }^{3}$ A direção de seu

*** NT: Conforme descrito por Foucault em História da sexualidade v. 2 - O uso dos prazeres, os "homens privilegiados" de que trata Buell seriam os indivíduos adultos livres do sexo masculino da sociedade grega, ou seja, a menor parte da população; a "estética da existência", por sua vez, consistiria na arte de se conduzir, que se dividiria nas três grandes técnicas desenvolvidas pelos gregos para esse fim: a Dietética, a Econômica e a Erótica.

3 Veyne plausivelmente comenta que "Foucault julgou tão indesejável quanto impossível ressuscitar essa ética; mas ele considerou que um de seus elementos, isto é, a idéia de um trabalho do 'eu' sobre o 'eu', seria capaz de readquirir um significado contemporâneo": "o eu, tomando-se como um trabalho a ser completado," ele supõe, "poderia sustentar uma ética que não pode mais ser apoiada nem pela tradição nem pela razão […]" (p. 7). 
pensamento, no entanto, não foi tão "invertida", como poderia parecer a princípio, uma vez que o espírito da obra de Foucault era irônico e, por vezes, de um ultraje nietzschiano contra as coações institucionais sobre a individualidade, mas certamente seus últimos escritos não apenas ressaltaram retrospectivamente a seriedade de seu interesse maior no destino do indivíduo como também marcaram sua nova receptividade ao ético como uma arena semiautônoma "não relacionada a qualquer sistema institucional social - ou pelo menos a qualquer sistema legal" e para relações de poder tidas como "móveis, reversíveis e instáveis" (1994, p. 255, 292). Este autoajuste antecipou - e provavelmente estimulou - a propensão de autores recentes a empregarem "ética" em oposição a "política" como um modo de teorizar o engajamento social baseado em princípios.

Outro sintomático olhar ético evidenciado por Foucault foi sua crítica incipiente sobre suas primeiras avaliações quanto à "idéia de verdade como nada mais que um estratagema a serviço de uma 'vontade de poder' epistêmica", como um mero artefato discursivo (NORRIS, 1994, p. 124, 126). Esta recente tendência teórica preocupa-se em expor os reducionismos intelectuais e os riscos morais do "ceticismo cognitivo absoluto" que supostamente caracterizaram o pós-estruturalismo (NORRIS, 1994, p. 3), evitando, ao mesmo tempo, os modelos ultrapassados do realismo mimético. Satya Mohanty, numa linha crítica independente, repudia enfaticamente a tendência do "ceticismo pós-modernista" "de negar experimentar qualquer valor cognitivo" e defende que, em especial no que se refere às narrativas de autores de povos oprimidos, "nós precisamos explorar a possibilidade de compreensão teórica da identidade social e cultural em termos do local social objetivo" (1997, p. 216, 234). O ímpeto mais forte para aqueles que procuram investigar se o discurso pode resultar em representações verdadeiras ou confiáveis, entretanto, tem sido mais derridaniano do que foucaultiano (ver a formulação de Mohanty sobre um realismo "póspositivista", p. 176-216); e até agora o posicionamento mais frequente tem sido o argumento - desenvolvido especialmente por estudiosos do póscolonialismo e do discurso das "minorias" - de que a verdade, autenticidade ou facticidade histórica está oculta dentro, ao lado ou por trás de discursos resistentes, opacos ou elípticos (CHOW, 1998, p. 39-41). Este parece ser o propósito da afirmação paradoxal de Gayatri Spivak de que "a ética é a experiência do impossível": uma representação ética da subalternidade deve ocorrer com a consciência de que o entendimento (mútuo) será limitado. Uma visão correlacionada é a concepção de Doris Sommer de uma "ética da retenção", através da qual autores de minorias resistentes criam disfarces e opacidades estratégicas para o leitor convencional - uma "poética da defesa", como George Yúdice a denomina em sua discussão sobre um dos ensaios de Sommer. 
Uma sexta linha de influência é a crescente autoconscientização sobre ética profissional, a qual tem estimulado debates nas universidades sobre padrões de conduta. No direito, as obras literárias vêm sendo utilizadas pedagogicamente, há algum tempo, como retratos mais adequados do pensamento e da conduta legal do que as fontes intradisciplinares usuais (por exemplo, WEISBERG; NUSSBAUM, 1995; conforme a crítica de POSNER, 1998, p. 305-332) - uma tendência espelhada em outros campos profissionais que ajudou a preparar o caminho (apesar de não ter sido uma influência direta) para o ousado e importante argumento de Wai Chee Dimock de que a "contextualização da justiça" dentro da literatura constitui uma reflexão ética mais profunda do que a "reificação da comensurabilidade", com a qual o discurso legal da justiça está comprometido (1996). Em um nível administrativo e instrumental, as associações literárias têm caminhado na direção de suas próprias reificações das preocupações ético-disciplinares na forma de códigos de conduta ética (por exemplo, a Modern Language Association of America - MLA). Finalmente, e de modo mais relevante, as preocupações com a ética da teoria e prática crítica têm sido acompanhadas por preocupações quanto à ética de conduta profissional (embora nem sempre sob o signo da ética em si) nos estudos de dimensões conceituais, históricas e pedagógicas da formação do cânone e suas modificações (SMITH; LAUTER; GUILLORY; JAY, G.). ${ }^{4}$

A revisão acima é, obviamente, um esboço incompleto. ${ }^{5}$ Mas deve bastar para mostrar que a ética, ao mesmo tempo em que vem se tornando um conceito privilegiado, também tem se tornado um conceito mais flexível

4 G. Jay não hesita em enquadrar as questões de canonicidade e suas implicações para a prática pedagógica como questões éticas, como quando ele discute a dinâmica professor-aluno em uma sala de aula intercultural (por exemplo, p. 143). Lauter, entretanto, tende a pensar em questóes envolvendo "dever" como ideológicas e, consequentemente, não reconhece a ética como uma esfera distinta e muito menos como uma esfera privilegiada. Do mesmo modo, Smith e Guillory demonstram uma preocupação central com as questões do "valor", mas com a atenção voltada mais para a dependência do estético ao econômico (dentro da história e discurso do capitalismo) do que para a "avaliação" como um projeto ético (todavia, ver SMITH, p. 158-166). O compromisso compartilhado por Lauter, Smith e Guillory (apesar de expresso de modo bastante diverso) de desempacotar o fenômeno dos controles sociais e institucionais sobre a interpretação distingue seus trabalhos daqueles da virada ética, no mínimo, tão acentuadamente como o faz Foucault em suas primeiras obras, embora, da mesma maneira, seus trabalhos pareçam também, em certo grau, prever aquela virada, especialmente se, por exemplo, o ponto de partida de alguém, como o de Jay (que cita os três com admiração), é a questão pragmática de "o que fazer após o fim do consenso e o advento do multiculturalismo" (p. 6). Até certo ponto, o livro American Literature and the Culture Wars, de Jay, pode ser considerado como a saga da consciência de uma sensibilidade pedagogicamente crítica que tenta transformar em aplicações práticas as análises acadêmicas de precursores como Lauter, Smith e Guillory. Nesse quadro, a ética e a política da prática crítica indubitavelmente convergem.

$5 \quad$ Entre as omissões mais claras inclui-se a relação dos estudos ético-literários contemporâneos com a desestabilização das categorias de gênero através das teorias feministas e homossexuais, com o dialogismo bakhtiniano, com a ética do discurso habermasiano e com a ecocrítica. 
e por isso potencialmente confuso. A ética como uma temática da representação moral difere claramente da ética como um "cuidar de si" e tampouco se equipara ao molde de procedimentos da ética profissional. Em parte, esta disparidade de foco pode refletir a relativa falta de fundamentação que os estudos ético-literários têm na ética como uma subdisciplina e uma tradição dentro da filosofia. Nenhum dos grandes filósofos éticos, desde Aristóteles até John Rawls, chamou mais a atenção daqueles que usualmente relacionam literatura e ética do que Derrida e Foucault (nenhum deles "eticista" no sentido estrito), com a exceção de Levinas, que preferiria ser visto como um pensador "metaético" do que como propriamente um "eticista". Em todo caso, uma vez que nenhum modelo específico para estudos dentro da ética é compartilhado por mais do que uma fração dos estudiosos que trabalham nos vários domínios da teoria e da crítica literária, é ainda mais surpreendente quando praticantes declarados da crítica ética se abstêm de relacionar (como frequentemente acontece) o seu entendimento particular de ética com as concepções alternativas existentes ou mesmo com as tradições antecedentes de temáticas morais, com a ideologia do gênero, com a ética desconstrutivista da leitura, com a política da canonicidade e daí em diante.

Entretanto, até hoje, ninguém parece haver se preocupado muito com o problema da cacofonia. Provavelmente com razão. Provavelmente uma certa discordância deva mesmo ser esperada de um discurso emergente (ou amontoado de discursos) que luta por sua autodefinição. Uma questão com uma disputa mais clara é se a voga ética, considerando-se que representa algo substancialmente novo, seria um avanço ou um retrocesso. A rápida ascensão da ética, com uma atenção maior do que obteve por várias décadas, pode ser e tem sido recebida tanto favoravelmente (por exemplo, como uma revalorização da consciência erudita e pedagógica, como um renascimento de uma antiga sensibilidade humanística notável, injustamente estigmatizada nos últimos anos, ou como uma importante nova teorização sobre a alteridade) quanto pejorativamente (por exemplo, como uma reprodução de um "majoritarianismo moral" ou como um recuo da política de transformação social para o "privatismo" (privatism), ou como o repúdio de Teresa L. EBERT (1996, p. 230, 301) ao "feminismo ético", visto como uma "mistificação lúdica" que apenas finge valorizar a alteridade numa, de fato, indulgência de seu próprio privilégio de classe). ${ }^{6}$

Independentemente de se estar inclinado a ter esperanças ou suspeitar das promessas da abordagem literária que privilegia a questão

$6 \quad$ Ebert cita aqui Cornell (p. 113), mas ela inclui no amplo alcance de sua crítica marxista todos os discursos teóricos, feministas ou não, que ela vê como o abandono da possibilidade de "uma política socialmente transformadora" em troca do "posicionamento da história como uma narrativa, como um evento discursivo" (p. 229-230). 
ética - seu florescimento e sua crescente valorização -, é conveniente que sejam avaliados seus diferentes contornos. Cinco deles parecem se destacar.

Primeiramente, a nova abordagem ética tende a favorecer a recuperação do papel do autor na produção de textos - sem esquecer, no entanto, que os textos são também, em certo sentido, construídos socialmente - e tende a defender, como Attridge, a importância da "autoria" (authoredness) para a teoria da escrita e, consequentemente, "com a permissão de Roland Barthes", de pensar-se na obra acima de pensar-se no texto (thinking "work" over thinking "text"). Em muitos outros ensaios (especialmente no de Albrecht, o que é compreensível tendo em vista o molde empírico de sua perspectiva histórico-literária), não apenas a "autoria”, mas também a figura do "autor histórico" é diretamente relevante. Mais claros como indicadores desse direcionamento são os ensaios de Bradley Butterfield e Mary Beth Tierney-Tello, ambos procurando diagnosticar a avaliação ética do pósmodernismo. No julgamento de Butterfield, que coloca Baudrillard diante de Ballard, a defesa de "uma crítica dos modelos de moralidade no capitalismo recente em prol de um senso mais profundo de liberdade pessoal e justiça através de uma revolução estética" está baseada no estabelecimento da distinção, especialmente na obra de Baudrillard, entre a aparência enganosa do texto "imoral" e o suposto posicionamento do escritor. No estudo elaborado por Tierney-Tello, que examina a possibilidade de uma política progressista do discurso pós-moderno, a obra de Diamela Eltit, por si só, apresenta-se claramente como a prova principal, não obstante, Tierney-Tello ainda ressalta a atenção ao autor histórico e a escrupulosidade etnográfica do pós-modernismo como evidências adicionais.

Mais central para a teoria e crítica com enfoque ético, acima inclusive da questão da atuação autoral, é a questão da responsabilidade da leitura, a qual, de fato, é frequentemente relacionada, como o faz Attridge, com a recuperação da autoria. A chave para muitas dessas vertentes de crítica ética é a concepção da literatura como sendo o outro do leitor, uma perspectiva da relação de leitura nitidamente diferente daquela da crítica tradicional baseada na reação do leitor, a qual tendia a focalizar (como Barthes fez) a apropriação ou a reinvenção do texto por parte do leitor. De modo geral, a crítica ética não encara a reinvenção nem como um jogo livre nem como uma afirmação de força, mas como consequência de um "ouvir" atento e consciente. Attridge propõe o modelo da "obra como um estranho/ desconhecido, mesmo [...] quando o leitor a conhece intimamente": um estranho ao qual se deve respeito. Sob o ponto de vista levinasiano, a obra é um outro na forma de um ato criativo para o qual os leitores são chamados a responsabilizarem-se, a permitirem-se um engajamento, até mesmo a ponto de serem, de certo modo, transformados. A partir de um modelo crítico 
diferente, derivado das teorias de resistência pós-colonialistas e de minorias, Tierney-Tello apresenta um argumento similar a respeito das versões vanguardistas de Eltit de "testimonio": elas dirigem ao leitor um "chamado eticamente fundamentado para a solidariedade" que - em parte por sua forte resistência às expectativas-padrão genéricas - pede ao leitor que ouça as vozes subalternas e veja as faces subalternas, mas não com a intenção de alcançar, processar e compreendê-las integralmente. ${ }^{7}$

De fato, uma das mais provocativas dimensões do ensaio teórico de Attridge e da exegese de Tierney-Tello é sua presteza em desenvolver ao máximo a imagem de comprometimento com o texto (obra) como se fosse um encontro com uma pessoa virtual. A hesitação com que Booth procedeu uma década antes - quando reviveu a metáfora vitoriana havia muito tempo adormecida do "livro como um amigo" (1988, p. 168-196), o que seria uma outra versão da noção geral da leitura como um ato interpessoal - agora parece menos necessária. Haney sequer vacila ao reivindicar um "significado genuinamente ético" para o fato de metáforas como "amigo" costumarem caracterizar obras literárias e ao reforçar a suposição levantada por HansGeorg Gadamer, em On the Contribution of Poetry to the Search for Truth, de que "o processo pelo qual a verdade de um poema é revelada é esclarecedoramente similar ao "dispor-se a estar aberto para [...] a verdade de outra pessoa', presente na hermenêutica ética."

A imagem do encontro textual como sendo um encontro pessoal não está livre de seus perigos, entre eles: a tentação de reificar a metáfora; a implicação de que a resistência do leitor é não-ética (um sintoma de obtusidade, de insensibilidade, de subdesenvolvimento ético); e uma adstringência voltada para estética, tal como mostrada por Levinas - o mais influente dos recentes teorizadores a respeito das relações entre o eu e o outro. ${ }^{8}$ Todavia, o modelo que define a experiência de leitura como uma cena de interpessoalidade virtual, a qual decreta, torna ativa ou, ao menos, ilumina a responsabilidade ética, pode, apesar dos perigos apresentados, mostrar-se uma das mais significantes inovações do movimento éticoliterário. Sendo assim, dois motivos podem ser destacados: a antiautoritária valorização da alteridade, que percorre o conjunto de estudos desde Levinas e da crítica pós-colonialista; e, como Attridge aponta, a insistência do modelo

\footnotetext{
$7 \quad$ Um modo diferente de ler a ética está sendo desenvolvido na linha do "cuidar de si" foucaultiano: a leitura como uma práxis de autodisciplina ou autodesenvolvimento.

$8 \quad$ Observando a autoridade que Levinas concede ao outro sobre o eu, Ricouer denuncia veementemente o que ele acredita ser a "hipérbole da exterioridade" em Otherwise Than Being, com sua concepção de um eu que necessita abrir-se para as incômodas insistências do outro. Observando o antiesteticismo de Levinas, sobre o qual Haney também comenta, Eaglestone faz uma tentativa corajosa ( $p$. 154-170) de redimir Levinas por suas expressões de desconfiança platônica nos artefatos como substituições da imagem pelo objeto, ao ressaltar sua valorização do "falar" (em Otherwise), a qual Levinas utiliza como metáfora para a expressividade ética. Entretanto, Eaglestone (como Haney) reconhece totalmente que é mais fácil defender Levinas como um tipo de artista verbal do que como um filósofo de uma estética ética.
} 
sobre a dinâmica do "eu-outro" como "uma relação ativa ou um evento".

Uma terceira dimensão dos estudos ético-literários recentes, mais conhecida, mas não menos importante, é o interesse em enxergar um ethos ou uma teleologia ética incipiente que estaria implícita em modos discursivos específicos (Butterfield), modelos de gênero (Tierney-Tello) ou estruturas formais no nível da obra individual (Tierney-Tello, Haney). Haney expõe essa ideia com detalhes ao redescrever uma seleção de projetos críticos e poéticos do Romantismo como expressões da bipolaridade aristotélica entre phronesis (sabedoria prática) e techne, uma bipolaridade que ele relaciona com a oposição entre imaginação e fantasia, alegando que o novo historicismo atropelou essa problemática com seu conceito de "pensamento estético como um trabalho cultural", uma redução da estética para a techne. A abordagem de textos literários como arena para a reflexão ética, por seu contorno formal ou genérico, também foi explorada em muitos outros trabalhos sobre literatura e ética, especialmente em estudos de gêneros narrativos (BOOTH, 1988; NUSSBAUM, 1990; 1995; NEWTON, 1995; 1996; HARPHAM, 1992, p. 157-182). Se existe alguma abordagem predominante para as leituras éticocríticas de obras literárias, provavelmente é esta.

Uma quarta preocupação dos estudos ético-literários aparece na analogia que Haney faz entre a interdependência semiantagônica de phronesis e techne e a distinção entre ética e moralidade - uma distinção, aliás, também comentada por Attridge. Ambos entendem a ética como uma sensibilidade ou orientação ética e veem a moralidade como um código de normas ("obrigações específicas regulando situações concretas em um contexto social", de acordo com Attridge). Todavia, Attridge quer distanciar ao máximo as duas noções, associando a ética com "imprevisibilidade e risco", enquanto Haney defende uma inseparabilidade essencial. Esta divergência, apesar do desejo comum de postular uma distinção, condensa a preocupação predominante dentro dos diálogos contemporâneos de literatura e ética em estabelecer que não deve prevalecer um conceito de responsabilidade que admita algum tipo de relação entre as categorias de ética e de moralidade. o empenho de Booth em descrever o caráter múltiplo das reações do leitor sem cair em relativismo crítico, a visão de Nussbaum de uma retórica jamesiana como um "diálogo entre percepção e norma (perception and rule)" (1990, p. 157), a ideia de Harpham de que o discurso confere imperatividade sem especificar obrigações particulares (1992, p. 5), e acima de tudo a concepção formulada por Levinas de responsabilidade pelo outro, significando "não a descoberta de um dado e sua recepção, mas a exposição do eu para o outro, antes de qualquer decisão" (1991, p. 141) - tudo isso parece trabalhar com/através da mesma problemática: determinar a relação entre disposição (disposition) e normatividade, seja a partir do ponto de vista do 
autor, do leitor, da linguagem ou das relações humanas. ${ }^{9}$

o problema, ou a possibilidade, do limite impreciso que se vislumbra quando se considera a distinção entre ética e moralidade é análogo ao (ou uma continuidade do) problema ainda mais intrigante da relação ou distinção entre o pessoal e o sociopolítico. Na realidade, todos os segmentos concordariam, aprovando ou não a "ética pós-moderna", que "o único espaço onde o ato moral pode ser realizado é o espaço social do 'ser com'” (BAUMAN, 1993, p. 185). Mas este consenso está longe de resolver a questão sobre se e como o ético implica ou não o político. Talvez o tema mais sensível, tanto para simpatizantes como para os opositores da voga ética, seja se esta vai reduzir-se, independentemente de qual corrente crítica esteja na "ordem do dia", a uma privatização das relações humanas que torne o social e o político elementos secundários. Ética é um significante irritantemente (ou fascinantemente?) ambidestro que aponta ao mesmo tempo para os domínios público e privado. Enquanto o interesse explícito de Foucault pela ética marcou uma mudança de atenção das estruturas de dominação para as práticas de autorrealização, a ética, para Levinas, como "primeira filosofia", pressupõe a prioridade da reivindicação do outro sobre o eu. Por um lado, Julia Kristeva compreende a ética como "a negativização do narcisismo por meio de uma prática; em outras palavras, uma prática é ética quando dissolve aquelas fixações narcisísticas (aquelas que estão estreitamente confinadas ao sujeito) para as quais o processo de significação sucumbe em sua relação sócio-simbólica" (p. 233). Entretanto, por outro lado, para Tobin Siebers, "a disciplina da ética permanece inextricavelmente misturada com o problema do caráter humano", de tal modo que, do ponto de vista da crítica ética, até mesmo "o desejo de eliminar o eu constitutivo da literatura tem motivações éticas das quais não se pode abdicar" (p. 5). Assim, como se pode perceber, a heterogeneidade teórica que anima a discussão éticoliterária contemporânea e alimenta as leituras críticas decorrentes transmite, como era previsível, sinais misturados - a tal ponto que alguns estudiosos da ética e da literatura passaram a preferir termos híbridos como "ético/ político" (adjetivo) (STEELE, 1997, p. 29, 112) ou "ética-política" (substantivo) (NEWTON, 1995; 1996).

Do mesmo modo, nos cincos ensaios desta publicação, o olhar ético manifesta-se como uma atenção (re)nova(da), por um lado, para o interpessoal como a base da leitura e da socialidade (Attridge) e para a reabilitação da autonomia estética como uma "autonomia ética" (Haney);

9 Isto, de modo algum, significa afirmar que todas as formas de estudos éticoliterários contemporâneos pressupõem o comprometimento com a compreensão "pós-moderna" de uma ética (BAUMAN, por exemplo, p. 10-15) não-embasada em códigos morais ou leis, que pressupõe o postulado de "um eu moral constituído pela responsabilidade" (p. 11). Levinas e Harpham provavelmente aceitariam essa premissa; Booth e Nussbaum provavelmente não. Entretanto, todos parecem intensamente interessados em ética-moralidade ou na problemática "códigos-disposição" (disposition-codes). 
e, por outro lado, para a dimensão sociopolítica de um filósofo visto, até recentemente, como um individualista (Albrecht, a respeito de Emerson) e para a estética ética tomada como uma intervenção política (Tierney-Tello).

É certo que o lugar do sociopolítico continuará a ser debatido dentro e em torno da crítica ética contemporânea. Pois não importa quão fortemente estudos ético-literários declarem a inseparabilidade do social e do pessoal, o "comprometimento", como um ponto de partida, continuará a parecer suspeitosamente privatista para muitos construcionistas sociais e culturais, isso sem mencionar os materialistas neomarxistas como Ebert. Os críticos éticos, provavelmente, permanecerão sob pressão para demonstrar como exatamente o "comprometimento" pode ser compreendido como potente não apenas "culturalmente", mas também histórica e politicamente.

Numa declaração que combina as duas polaridades dos substantivos "ética/moralidade" e dos adjetivos "ético-moral/político", Levinas reúne habilmente o desejo de construir uma visão social sobre o comprometimento para com o outro e os riscos nisso envolvidos. "Moralidade", ele afirma, "é o que comanda o mundo do interesse político"; mas "a norma que deve continuar inspirando e direcionando a ordem moral é a norma ética do inter-humano", a qual, ele admite, "não pode, por si só, criar leis para a sociedade ou produzir regras de conduta segundo as quais a sociedade poderia ser revolucionada ou transformada", mas que, apesar disso, é a base da "ordem moral-política", sem a qual esta ordem "deve aceitar todas as formas de sociedade, inclusive as fascistas ou totalitárias, pois não é mais capaz de avaliá-las ou diferenciá-las" (1995, p. 194-195). Como os comentários (bastante breves) de Levinas sobre justiça social tornam mais claro (1991, p. 157-161), ele considera a justiça social uma indispensável, mas derivada codificação da inter-humanidade. Este modo de pensar provoca ao menos três críticas. Primeiro, ele é autocontraditório: insiste no "antifundamentalismo", mas apresenta um fundamento (interhumanidade) para se proteger contra a suposição que pode ser levantada, como Niall Lucy demonstra (1997, p. 204-210), a partir de uma concepção puramente relativista da ética: "o fascismo é uma ética, embora possa não ser uma que muitos de nós escolheríamos para defender" (p. 236). Entretanto, mesmo perdoando isto, Levinas é vulnerável ainda em ao menos dois aspectos. De um lado (o esquerdo, basicamente), vem esta réplica: Como podem os preceitos morais (por exemplo, respeitar o clamor do outro) formar as bases de coletividades sociais e, ao mesmo tempo, assegurar uma reforma da sociedade ou da política? E, mesmo que pudessem, será que não existe mesmo alguma coisa opressivamente homogeneizante, se não totalizante, no "outro" de Levinas? Irigiray (p. 116) declara: "O outro, (como) mulher, não percebe a existência 'dela'” (the other, (as) woman, he does not notice 
her existence).$^{10}$ Do outro lado (o direito, basicamente), vem esta interrogação: Quão ético é o ethos de permitir que alguém seja retido como refém, sem a mutualidade de comprometimento pessoal ou sem um contrato social na base disto? Desse ponto de vista, vincular alguém ao outro aniquila não apenas o individualismo moral (RICOUER, ver nota 8), mas, potencialmente, também o outro, pois, "a menos que você tome os outros como responsáveis pelos fins que escolhem e pelas ações que realizam, você não pode respeitálos como agentes morais e racionais e, então, você não os tratará como fins neles mesmos". (KORSGAARD, 1996, p. 206)

Duas previsões podem ser feitas com alguma segurança. A primeira é que a cena da interpessoalidade, ou inter-humanidade, para a qual a crítica ética corrente tem sido fortemente atraída, continuará a exercer seu poder, assim como a crítica dos paradigmas de textualidade dos anos 1970 e historicismo dos anos 1980 seguem seus cursos, e as pressões internas (ver Levinas) e externas (ver Ebert) ou continuarão fazendo força para tornar a eticidade mais responsável sociopoliticamente ou esquecerão isto definitivamente. A segunda é que a longevidade da questão ético-literária dependerá bastante de sua capacidade ou de se autocorrigir ou de ser corrigida, como exemplo, a ênfase na inter-humanidade deverá ser mais bem sintetizada com a ética social e/ou política. Enquanto isso, a partir dos diálogos entre literatura e ética já realizados, ainda há muito que aprender, muito mais do que esta introdução pode dar conta.

\section{REFERÊNCIAS}

AUGST, Thomas. Taking society out of books: character, self-fashioning, and the rhetoric of market culture in Nineteenth Century America. Dissertation. Harvard, 1997.

BAUMAN, Zygmunt. Postmodern ethics. Oxford: Blackwell, 1993.

BERNASCONI, Robert; CRITCHLEY, Simon (Eds.). Re-reading Levinas. Bloomington: Indiana, 1991.

BоOTH, Wayne. The company we keep: an ethics of fiction. Chicago: University of Chicago Press, 1988.

The rhetoric of fiction. Chicago: University of Chicago Press, 1961.

CHALIER, Catherine. Ethics and the feminine. Bernasconi and Critchley, p. 119-129.

CHANTER, Tina. Antigone's dilemma. Bernasconi and Critchley, p. 130-136.

CHOW, Rey. Ethics after idealism: theory, culture, ethnicity, reading. Bloomington: Indiana University Press, 1998.

10 Ver, todavia, a defesa de Chalier para o feminismo de Levinas e a avaliação equivocada de Chanter, no mesmo volume. Spivak é ainda mais categórico que Irigiray, afirmando que, para Levinas, todo o "sujeito (subject-ship) da ética é absolutamente masculino" (1992, p. 76) 
BUELL, L. EM BUSCA DA ÉTICA

CORNELL, Drucilla. Beyond accommodation: ethical feminism, deconstruction, and the law. New York: Routledge, 1991.

CRITCHLEY, Simon. The ethics of deconstruction: Derrida and Levinas. Oxford: Blackwell, 1992.

De MAN, Paul. Wartime journalism, 1939-1943. Ed. Werner Hamacher, Neil Hertz, and Thomas Keenan. Lincoln: University of Nebraska Press, 1988.

DERRIDA, Jacques. Adieu. Critical Inquiry, n. 23, p. 1-10, 1996.

The force of law: the mystical foundation of authority. Trad. Mary Quaintance. In: CORNELL, Drucilla et al. (Eds.). Deconstruction and the possibility of justice. New York: Routledge, 1992. p. 68-91.

. The gift of death. Trad. David Wills. Chicago: University of Chicago Press, 1995.

The other heading: reflections on today's Europe. Trad. Pascale-Anne Brault e Michael B. Naas. Bloomington: Indiana University Press, 1992.

Spectres of Marx: the state of debt, the work of mourning, and the new international. Trad. Peggy Kamuf. New York: Routledge, 1994.

Violence and metaphysics: an essay on the thought of Emmanuel Levinas. In: Writing and difference. Trad. Alan Bass. Chicago: University of Chicago Press, 1978. p. 79-153.

DIMOCK, Wai Chee. Residues of justice: literature, law, philosophy. Berkeley: University of California Press, 1996.

EAGLESTONE, Robert. Ethical criticism: reading after Levinas. Edinburg: Edinburg University Press, 1997.

EBERT, Teresa. Ludic feminism and after: postmodernism, desire, and labor in late capitalism. Ann Arbor: University of Michigan Press, 1996.

FOUCAULT, Michel. The care of the self. Trad. Robert Hurley. New York: Random, 1986.

Ethics: subjectivity and truth. Trad. Robert Hurley et al. Ed. Paul Rabinow. New York: New, 1994.

The use of pleasure. Trad. Robert Hurley. New York: Viking, 1985.

GUILLORY, John. Cultural capital: the problem of literary canon formation. Chicago: University of Chicago Press, 1993.

HARPHAM, Geoffrey. Ethics. In: LENTRICCHIA, Frank, MCLAUGHLIN, Thomas (Eds.). Critical terms for literary study. 2. ed.. Chicago: University of Chicago Press, 1995. p. 387405. Press, 1992.

Getting it right: language, literature, and ethics. Chicago: University of Chicago

IRIGIRAY, Luce. Questions to Emmanuel Levinas: on the divinity of love. Bernasconi and Critchley, p. 109-118.

JAY, Gregory. American literature and the culture wars. Madison: University of Wisconsin Press, 1996.

JAY, Martin. Force fields: between intellectual history and cultural critique. New York: Routledge, 1993.

JOHNSON, Barbara. A world of difference. Baltimore: John Hopkins University Press, 1987. 
KORSGAARD, Christine M. Creating the kingdom of ends. Cambridge: Cambridge University Press, 1996

KRISTEVA, Julia. Revolution in poetic language. New York: Columbia University Press, 1984.

LAUTER, Paul. Canons and contexts. New York: Oxford University Press, 1991.

LEVINAS, Emmanuel. Ethics of the infinite. Interview with Richard Kearney. In: KEARNEY, R. States of mind: dialogues with contemporary thinkers. New York: New York University Press, 1995. p. 177-199. $\overline{1991 .}$

Otherwise than being: or, beyond essence. Trad. Alphonso Lingis. Dordrecht: Kluwer, 1969.

Totality and infinity. Trad. Alphonso Lingis. Pittsburgh: Duquesne University Press,

LUCY, Niall. Postmodern literary theory: an introduction. Oxford: Blackwell, 1997.

MILLER, J. Hillis. The ethics of reading: Kant, de Man, Eliot, Trollope, James, and Benjamin. New York: Columbia University Press, 1987.

. Versions of Pygmalion. Cambridge: Harvard University Press, 1990.

MODERN Language Association of America. Statement of Professional Ethics. In: Profession 92. New York: MLA, 1992. p. 75-78.

MOHANTY, Satya P. Literary theory and the claims of history: postmodernism, objectivity, multicultural politics. Ithaca: Cornell University Press, 1997.

NEALON, Jeffrey T. The ethics of dialogue: Bakhtin and Levinas. College English, n. 59, p. 129-147, 1997.

NEWTON, Adam Zachary. From exegesis to ethics: recognition and its vicissitudes in Saul Bellow and Chester Himes. South Atlantic Quarterly, n. 95, p. 979-1008, 1996.

. Narrative ethics. Cambridge: Harvard University Press, 1995.

NORRIS, Christopher. Truth and the ethics of criticism. Manchester: Manchester University Press, 1994.

NUSSBAUM, Martha. Love's knowledge: essays on philosophy and literature. New York: Oxford University Press, 1990.

Poetic justice: the literary imagination and public life. Boston: Beacon, 1995.

PARKER, David. Ethics. Theory and the novel. Cambridge: Cambridge University Press, 1994.

PATTERSON, Anita Haya. From Emerson to King: democracy, race, and the politics of protest. New York: Oxford University Press, 1997.

PHELAN, James. Narrative as rhetoric: technique, audiences, ethics, ideology. Columbus: Ohio State University Press, 1996.

POSNER, Richard. Law and literature. ed. rev. Cambridge: Harvard University Press, 1998.

RICOUER, Paul. Oneself as another. Trad. Kathleen Blamey. Chicago: University of Chicago Press, 1992.

RORTY, Richard. Consequences of pragmatism. Minneapolis: University of Minnesota Press, 1982.

Contingency, irony, and solidarity. Cambridge: Harvard University Press, 1989. 
BUELL, L. EM BUSCA DA ÉTICA

SIEBERS, Tobin. The ethics of criticism. Ithaca: Cornell University Press, 1988.

SMITH, Barbara Herrnstein. Contingencies of value: alternative perspectives for critical theory. Cambridge: Harvard University Press, 1988.

SOMMER, Doris. Resisting the heat: Menchú, Morrison, and incompetent readers. In: KAPLAN, Amy; PEASE, Donald E. (Eds.). Cultures of United States imperialism. Durham: Duke University Press, 1993. p. 407-432.

Textual conquests: on readerly competence and "minority" literature. Modern Language Quarterly, n. 54, p. 141-153, 1993.

SPIVAK, Gayatri. French feminism revisited: ethics and politics. In: BUTLER, Judith; SCOTT, Joan W. (Eds.). Feminists theorize the political. New York: Routledge, 1992. p. 54-85.

Translator's preface. In: DEVI, Mahasweta. Imaginary maps. Trad. e ed. Spivak. New York: Routledge, 1995. p. xxiii-xxix.

STEELE, Meili. Theorizing textual subjects: agency and oppression. Cambridge: Cambridge University Press, 1997.

VEYNE, Paul. The final Foucault and his ethics. Trad. Catherine Porter and Arnold I. Davidson. Critical Inquiry, n. 29, p. 1-9, 1993.

WEISBERG, Richard. Poethics. New York: Columbia University Press, 1992.

WEST, Cornell. The American evasion of philosophy. Madison: University of Wisconsin Press, 1989.

YÚDICE, George. Marginality and the ethics of survival. In: ROSS, Andrew (Ed.). Universal abandon? The politics of postmodernism. Minneapolis: University of Minnesota Press, 1988. p. 214-236.

Enviado em: 21/03/2007

Aceito em: 30/02/2009 